\title{
Conclusion: Asking the Right Questions
}

\author{
Joachim Boldt, Annelieke Driessen, Björn Freter, \\ Tobias Haeusermann, Franziska Krause, Pei-Yi Liu, \\ Tim Opgenhaffen, and Annekatrin Skeide
}

Care is an important part of daily healthcare practices and the selfunderstanding of those working in the healthcare sector. At the same time, the notion of care carries an extraordinary range of distinctive meanings, as the preceding chapters have made clear. Indeed, definitions of care and its associated practices have often been so broad that

This conclusion was jointly written by the following contributors to this book (in alphabetical order): Boldt, Joachim; Driessen, Annelieke; Freter, Björn; Haeusermann, Tobias; Krause, Franziska; Liu, Pei-Yi; Opgenhaffen, Tim; Skeide, Annekatrin. Tobias deserves special mention for writing the first draft.

J. Boldt $(\bowtie) \bullet$ F. Krause

Department of Medical Ethics and the History of Medicine, University of Freiburg, Freiburg, Germany

A. Driessen

Amsterdam Institute for Social Science Research (AISSR), University of Amsterdam, Amsterdam, The Netherlands

B. Freter

Independent Scholar, Berlin, Germany

(C) The Author(s) 2018 
care may be found everywhere and in everything, including at times in the most unexpected places. Alternately, definitions have also been so narrow that one finds it hard to go beyond a limited set of questions, remaining instead within the confines of a single discipline. Although this makes it difficult to come up with a precise definition of care, it does not imply that it is impossible to describe care in words at all.

The philosophical and ethical accounts in part one of this book agree that the dyadic relation between a person in need and a person who provides help is one of the core elements of care. For example, in her contribution, Krause demonstrates how the account of interpersonal relationality supplied by the philosopher and phenomenologist Emmanuel Levinas can be useful for discussions of care in healthcare ethics. Levinas claims that any encounter with another person inherently involves having to assume responsibilities for this other person. In the same vein, by drawing on the conceptual resources of phenomenology, Freter lays bare basic structures of the encounter of one person with another in his analysis of the biblical story of the Good Samaritan. The hermeneutic tradition often stresses that the way in which humans epistemically and physically relate to one another is reciprocal and invokes relational dependencies, with the writings of Paul Ricoeur serving as a prime example of this. In his analysis, Boldt describes and interprets these relational dependencies within Ricoeur's concept of the self. In his chapter, Maio shows how Ricoeur's approach is closely connected to the detailed understandings of

\section{T. Haeusermann}

Epidemiology, Biostatistics \& Prevention Institute (EBPI), University of Zürich, Zürich, Switzerland

P.-Y. Liu

Faculty of Nursing, Philosophisch-Theologische Hochschule Vallendar (PTHV), Vallendar, Germany

\section{T. Opgenhaffen}

Institute for Social Law, Katholieke Universiteit Leuven, Leuven, Belgium

\section{A. Skeide}

Human and Health Sciences, University of Bremen, Bremen, Germany 
care that Joan Tronto develops in her political theory of care. Finally, in her reconstruction of historical precursors to today's thinking in care ethics, Conradi unveils the significant contributions of reflections about care made by Jewish women who were part of the social care and social reform movements of the late nineteenth and early twentieth century. As Conradi argues, these often overlooked reflections are closely connected, for example, to the theory of the I-You-relation as devised by the Jewish philosopher and theologian Martin Buber.

Even if one assumes that it is possible to point to core elements of care, as the chapters in part one of the book attempt to do, these descriptions alone cannot supply simple solutions to the challenges that are rooted in the ambivalences and tensions of the notion of care in healthcare. Sociologists and anthropologists, among others, have long been interested in showing how extensive, situated, and complex care can be. The chapters in part two of this book address questions that arise in these disciplines, as well as in disciplines such as nursing sciences and law, including: If there is a situation in which a caregiver reacts to another person's needs and provides help, can the care practices include coercion? And if so, when and where is this the case? Is care compatible with exclusion? Can it be passive or invisible? Can it be incorporated into standardised and regulated routines? Can the care vocabulary be adapted to medical terminology?

Looking back at all of the chapters in this book, the following key ambivalences and tensions of care in healthcare emerge:

\section{Caring, Influencing, and Coercing}

Caring for another person necessarily implies influencing the other person's abilities or their desires. For example, someone who receives help may be able to do what they could not do before. He or she might be in a better mood, experience gratitude, or feel burdened by social expectations to repay the help that was received. When the caregiver and care receiver discuss rehabilitative or therapeutic options, they imagine and perhaps adjust what they want for themselves and for one another accordingly. 
Sometimes the actions that a caregiver considers to be in the overall interest of the care receiver might not coincide with the initial will of the person receiving care. Nobody doubts that a nurse who supports the daily activities of someone who is temporarily or permanently disabled is providing care. Care is self-evident here. It is the nurse's job. But what if the nurse tricks a patient who does not want to get up into getting up anyway? Although providing care in this case may appear paternalistic, can it still be a response to a need? As Driessen's chapter exemplifies, in these cases, caregiving may include attempts to influence a patient's wishes, to encourage him or her not only to stop resisting what the caregiver perceives to be good care, but to actually want it. The line that separates these practices from practices involving unjustified manipulation or even coercion is a fine one. Indeed, Driessen contends that with regard to dementia, good care involves attempting to avoid coercion, even if such attempts sometimes fail.

Writing about the psychiatric emergency ward, Opgenhaffen argues that is not always self-evident that coercion never can be part of good care. In search of an ethical foundation for handling coercion, he maintains that in extreme cases, coercion which aims at restoring autonomy might, in fact, be conducted in a caring way. Although from a care perspective manipulation and coercion must, prima facie, be avoided, since they harm another person both physically and psychologically, even these actions may be justifiable from the point of view of care if there is immediate danger to the life and health of others or of the person concerned. As Opgenhaffen points out, clearly identifying and defining such circumstances, and maintaining a caring attitude that places the needs of the person in question before safety concerns, may help to minimise the dehumanising aspects of coercion.

Drawing the line between justifiably influencing the will of a care receiver in order to maintain what one regards to be the person's overall well-being on the one hand, and manipulation and coercion on the other hand, is tantamount to making a distinction between the kinds of relationality that are constitutive of, or at least compatible with, human autonomy and the kinds of relationality that impede autonomy. As Boldt argues, autonomy is based on social conditions and comprises elements 
of social dependencies. It is therefore a mistake to place valuing autonomy in opposition to valuing care. If one is concerned about the autonomy of oneself and others, one ought to be concerned as well about the wellbeing of oneself and others, and the care provided to oneself and others. Still, it is impossible to define this approach in abstract terms. Instead continuous everyday reflective and practical efforts are needed when providing care in healthcare settings.

\section{Care, Inclusion, and Exclusion}

At first glance, care practices seem to be prime examples of inclusive activities. When caring for another person, one turns to another person, appreciates their needs and interests, and acts in an attempt to improve their situation. Such acts ideally enable care receivers to keep up their daily lives and thus to maintain or return to their positions as members of all those social groups to which they belong.

Nonetheless, care may also contribute to social exclusion. As the dementia village described by Haeusermann exemplifies, care receivers may feel happy in surroundings that in effect exclude them from their own neighbourhoods and social groups. Haeusermann points out that while the dementia village aims to give its inhabitants the impression of an inclusive, "normal" village life, this village is also surrounded by a fence.

Is it appropriate to isolate certain vulnerable groups from the majority at a societal level? When approaching this question, it soon becomes clear that a one-dimensional conception of social exclusion does not lead to fruitful results. Rather, we need to consider the multiple levels at which exclusion and inclusion are realised simultaneously. People with dementia can be included by virtue of a state's provision of affordable medical care. At the same time, they can be excluded from their local community or family through a gated institution. Meanwhile, the elderly can remain included in their social network by living with their families or within community care projects, but be denied appropriate medical care offered by the state. Future analyses of care and care prac- 
tices need to take a close look at exclusion that stems from caring, its relation to the individual will, and its effects on individual well-being and on societal cohesion.

\section{Care, Passivity, and Invisibility}

Is what we call care always visible? Sometimes it is visible in what is done. In those cases passivity may appear to indicate a neglect of care. However, upon closer inspection, passivity can be a very important part of care as well. The most obvious example is listening to and observing what a patient says or expresses nonverbally. Care always involves phases of passivity in which one gets to know the other person and his or her preferences and needs. What is more, in some cases, passively being with, observing, and not intervening can be considered an integral part of actively caring, as Skeide demonstrates in her contribution on midwifes who accompany labouring women. Here, being with can be understood as a caring intervention.

In other cases, it might be helpful if care receivers are not aware of the caregiver's presence. Care in these cases is supplied by making itself invisible. The policy in the dementia care village described by Haeusermann prescribed that care workers work without uniforms. In the dementia village, what is allowed to be visible is the "normal", common structure of typical everyday life in the German countryside (or at least the stereotypical, utopian conception of it). Meant to support the inhabitants' well-being, this nonetheless resulted in uneasiness among some care workers, who felt the policy nullified their educational efforts. Moreover, for the residents and their family members, the absence of a clear care authority could lead to situations in which they do not know who to turn to.

In general terms, although care might at times appear to be invisible or passive, only the person who is seeking care can determine whether such invisible or passive care constitutes neglect or reassurance. The ambivalence between caring actively and passively, visibly and invisibly, thus requires a cautious approach in any analysis of instances in which care is provided. 


\section{Care, Regulation, Standardisation, and Fragmentation}

Care in healthcare is a professional activity that takes place in a context of regulation and standardisation. This helps to safeguard, among other things, patient rights, a just distribution of care provisions, and the longterm economic stability of the healthcare system. Nonetheless, regulation can interfere with the provision of optimal care in individual cases. Moreover, following regulations without understanding their relation to the value of care can lead to attitudes and actions that neglect this value. As mentioned above with regard to coercion in psychiatry, Opgenhaffen contends that if coercion is understood as a borderline case of care in which one still needs to take into account the well-being of the patient, this can help to minimise the dehumanising aspects of coercive measures.

What is more, given the importance of the individual and personal aspects of giving and receiving care, it will always be necessary to balance abstract regulation on the one hand and individual context-sensitive decisions on the other hand. This is to say that regulating care in healthcare settings must always leave room for responsible, individual decisions by the caregiver.

Standardised care practices often go hand in hand with fragmented distributions of responsibility and authority. As Liu shows with respect to ambulant diabetes care, nurses are responsible for the daily care and wellbeing of their patients in many respects. At the same time, their authority to administer therapies is limited, and patients accordingly do not regard nursing staff recommendations as authoritative expert statements on par with the statements of physicians.

Finally, standardisation does not only have an effect on the relation of caregiver to care receiver. As van der Meide argues, it also concerns the spaces in which care is provided. Although rooms and routines in the hospital are needed to facilitate efficient care procedures, standardised spaces may also compromise the well-being and healing processes of patients. 


\section{Care, Language, and Ambiguity}

Communication in healthcare is dominated by medical terminology, which aims to precisely define and refer to diseases, therapies, and physiological facts. This terminology and its aims are an indispensable part of statistical surveys, economic classifications as well as efficient and errorfree expert communication. In contrast, the language that is used to denote practices of care and the language that is used in providing care can appear to lack this kind of precision.

Since care practices are part of an institutional setting that involves experts, distribution of labour, and expert exchanges, some would argue that a lack of precision represents a disadvantage. In this context, they would surmise that care language needs to strive for accuracy just as medical terminology does. At the same time, however, the language of care that is used in care practices is necessarily close to everyday language since it has to do with everyday activities that are not confined to the healthcare setting. Moreover, it involves the experiences and perceptions of patients as described in their own words. The way patients express their experiences can vary according to their prior life experiences, their convictions, and their knowledge. The vocabulary they use may be part of a larger narrative, rather than comprising single terms that refer to clearly delineable states of affairs. As the relevant discourses show, the value of narrative self-identity, embodied knowledge, and patient knowledge should not be neglected.

While this ultimately may be an unresolvable tension, Kohlen highlights the fact that in today's healthcare settings, striving for accuracy prevails over the acceptance of ambiguity. Given the focus on economic measures, core elements of care that are subject to ambiguity are often regarded as irrelevant. The voices of caregivers are thus underrepresented in todays' healthcare institutions, as Kohlen demonstrates in the case of hospital ethics committees.

\section{Concluding Remarks}

Identifying and describing the tensions and ambivalences of care, as this book has done, is not tantamount to resolving these issues. Indeed, as has been argued, many of the tensions described may be inevitable and unre- 
solvable both in theory and in practice. Anyone working in and thinking about today's healthcare settings will always be challenged in their selfunderstanding and daily practices to find ways to adequately deal with these tensions. However, asking the right questions may open doors to more attuned understandings of the complexities and challenges of care. To pose these questions and deal with these challenges, then, is a form of caring about care. This is what this book aimed to do.

Open Access This chapter is licensed under the terms of the Creative Commons Attribution 4.0 International License (http://creativecommons.org/licenses/ by/4.0/), which permits use, sharing, adaptation, distribution and reproduction in any medium or format, as long as you give appropriate credit to the original author(s) and the source, provide a link to the Creative Commons license and indicate if changes were made.

The images or other third party material in this chapter are included in the chapter's Creative Commons license, unless indicated otherwise in a credit line to the material. If material is not included in the chapter's Creative Commons license and your intended use is not permitted by statutory regulation or exceeds the permitted use, you will need to obtain permission directly from the copyright holder. 